А.А.Шульдяков ${ }^{1}$, Е.П.Ляпина ${ }^{1}$, В.И.Кузнецов ${ }^{1}$, М.К.Ерофеева ${ }^{2}$, М.Г.Позднякова ${ }^{2}$, В.Л.Максакова ${ }^{2}$, О.С.Котова ${ }^{2}$, С.Е.Шелехова ${ }^{2}$ Ж.В.Бузицкая ${ }^{2}$, И.В.Амосова ${ }^{2}$, А.Ю.Гиль ${ }^{3}$

Клинико-эпидемиологическая эффективность противовирусного препарата Ингавирин ${ }^{\circledR}$

1 - ГБОУ ВПО "Саратовский государственный медицинский университет им. В.И.Разумовского" Минздравсоцразвития России: 410012, Саратов, ул. Большая Казачья, 112;

2 - ФГБУ "НИИ гриппа" Минздравсоцразвития России: 197376, Санкт-Петербург, ул. проф. Попова, 15 / 17;

3 - ГОУ ВПО "Первый Московский государственный медицинский университет": 119021, Москва, Зубовский оульвар, 37 / 1

\author{
A.A.Shuldyakov, E.P.Lyapina, V.I.Kuznetsov, M.K.Erofeeva, M.G.Pozdnyakova, V.L.Maksakova, O.S.Kotova, \\ S.E.Shelekhova, Zh.V.Buzitskaya, I.V.Amosova, A.Yu.Gil
}

\title{
Clinical and epidemiological efficacy of antiviral drug Ingavirin
}

\begin{abstract}
Summary
A randomized double-blind placebo controlled trial of efficacy and safety of Ingavirin (capsules, $90 \mathrm{mg}$, Valenta Pharm, Russia) administered for urgent intrafocal prevention of the disease during breaks of influenza and other acute respiratory viral infections (ARVI) in adults. The results have shown that Ingavirin is effective for intrafocal prevention of ARVI in healthy subjects in an epidemic focus. Seven-day course of the drug significantly decreased morbidity among exposed subjects by $63 \%$ and a risk of ARVI 2.7 times; the efficacy index 2.7 ; relative risk 0.37 . In patients developed ARVI after preventive treatment with Ingavirin, the duration of fever was 1 day shorter and the course of ARVI was milder. Ingavirin effectively prevented exposed subjects from ARVI in an epidemic focus and was active against a wide spectrum of influenza and other respiratory viruses (adenovirus, parainfluenza virus). Key words: respiratory viral infections, urgent prevention.
\end{abstract}

\section{Резюме}

Было проведено двойное слепое рандомизированное плацебоконтролируемое исследование по оценке эффективности и безопасности препарата Ингавирин ${ }^{\circledR}$, капсулы 90 мг (ОАО "Валента Фарм", Россия) для экстренной внутриочаговой профилактики в период подъема заболеваемости гриппом и другими острыми респираторными вирусными инфекциями (ОРВИ) у взрослых. Результаты исследования свидетельствуют о том, что противовирусный препарат Ингавирин ${ }^{\circledR}$ является эффективным средством внутриочаговой профилактики острых респираторных вирусных заболеваний (ОРВ3) среди контактных лиц в эпидемическом очаге. При ежедневном приеме в течение 7 дней препарат достоверно снижает заболеваемость среди контактных лиц на $63 \%$ и уменьшает риск развития ОРВ3 в 2,7 раза (индекс эффективности - 2,7; относительный риск - 0,37). У заболевших контактных лиц, принимавших в качестве профилактического средства Ингавирин ${ }^{\circledR}$, продолжительность периода лихорадки была на сутки короче, наблюдалось более легкое течение ОРВЗ. Препарат эффективно защищает контактных лиц от заболевания в очаге инфекции, обладает широким спектром активности в отношении вирусов гриппа и эпидемически наиболее значимых ОРВИ негриппозной этиологии (аденовирус, вирус парагриппа).

Ключевые слова: Ингавирин ${ }^{\circledR}$, респираторная вирусная инфекция, экстренная профилактика.

Острые респираторные вирусные инфекции (ОРВИ), включая грипп, продолжают оставаться актуальной медицинской и социально-экономической проблемой. Воздушно-капельный механизм передачи обусловливает их повсеместное распространение и высокую интенсивность эпидемического процесса. Эта группа инфекций наносит огромный ущерб здоровью населения и экономике стран. За эпидемический период заболевает до 20 \% населения. По данным Всемирной организации здравоохранения (ВО3), ежегодно в период эпидемий регистрируется 3-5 млн случаев тяжелой болезни и 250 000-500 000 случаев смерти.

Число больных с тяжелыми и осложненными формами гриппа значительно возрастает в период пандемий [1]. В период пандемии 2009 г. по официальной информации ВО3, Американского (CDC) и Европейского (ECDC) центров контроля заболеваний, количество лабораторно подтвержденных летальных случаев в мире составило более 16,9 тыс. В России, по данным официальной статистики (форма государственного статистического наблюдения № 1 "Сведения об инфекционных и паразитарных заболеваниях"), за период пандемии (октябрь- декабрь 2009 г.) острыми респираторными вирусными заболеваниями (ОРВ3) переболели 13,26 млн человек (4,09 \% от общей численности населения), что на 5,82 млн больше, чем за аналогичный период 2008 г. В структуре лабораторно подтвержденных случаев гриппа А / H1N1 / 09 в РФ взрослое население составило $60,5 \%$, при этом наибольшее количество заболевших взрослых было в возрасте 18-39 лет (44,2 \% от лабораторно подтвержденных случаев). Среди заболевших детей преобладали школьники в возрасте 7-14 лет $(17,2 \%)$ и подростки 15-17 лет $(8,7 \%)[2]$.

OРВ3 негриппозной этиологии могут быть обусловлены большим числом (около 200) вирусов, среди которых ведущее значение имеют рино- и аденовирусы, вирусы парагриппа, респираторно-синцитиальный вирус. В течение последних лет были идентифицированы новые, ранее неизвестные, возбудители респираторных инфекций, к числу которых относятся метапневмовирус и бокавирус человека [3-5]. Эти инфекции распространены повсеместно, спорадические случаи регистрируются в течение всего года с подъемом заболеваемости в осенне-весенний пери- 
од. Тропизм вирусов к различным отделам респираторного тракта обусловливает особенности и тяжесть клинических проявлений и нередко развитие жизнеугрожающих осложнений [6-9]. На тяжесть течения OPB3 влияет множество факторов: генетическая и антигенная характеристика возбудителя, хронические заболевания сердечно-сосудистой системы, органов дыхания, сахарный диабет, ожирение, онкологические и другие заболевания. К группами риска тяжелого течения и развития осложнений болезни относятся дети в возрасте до 5 лет и беременные женщины. В качестве особо уязвимой группы необходимо рассматривать пациентов с крайне ослабленным иммунитетом, как высокочувствительных к инфекциям и плохо поддающихся лечению. Кроме того, у них с большей вероятностью формируется устойчивость к противовирусным препаратам [10]. Поэтому важным является проведение превентивных мероприятий с целью снижения частоты и выраженности ОРВ3, а также предотвращения вторичных осложнений у пациентов, входящих в группу риска.

Вследствие высокой изменчивости антигенной структуры циркулирующих вирусов гриппа и гетерогенности возбудителей ОРВ3, способности изменять свои свойства и патогенность эти заболевания остаются практически неконтролируемыми. Невозможность создания вакцины против большинства возбудителей вирусных инфекций диктует необходимость поиска путей профилактики и лечения этой группы заболеваний лекарственными средствами с широким спектром противовирусной активности.

Ингавирин ${ }^{\circledR}$ - отечественный противовирусный препарат, активный компонент которого является низкомолекулярным соединением, аналогом природного пептидоамина, выделенного из нервной ткани морского моллюска Aplysia californica (синтезирован в Московской государственной академии тонкой химической технологии им. М.В.Ломоносова). Препарат разрешен к применению с 2008 г. В эксперименте показана его эффективность в отношении штаммов вируса гриппа А (H1N1, H1N1swl, H3N2, H5N1), гриппа В, аденовирусной инфекции, парагриппа, респираторно-синцитиальной инфекции [11-14]. Получены данные о терапевтической эффективности противовирусного препарата у госпитализированных больных гриппом, а также ОРВ3 [15-17].

Целью настоящего исследования явилась оценка профилактической эффективности Ингавирина ${ }^{\circledR}$ в очагах ОРВИ в период подъема заболеваемости.

\section{Материалы и методы}

В период с октября 2010 г. по апрель 2011 г., во время эпидемического подъема заболеваемости ОРВИ было проведено двойное слепое рандомизированное плацебоконтролируемое исследование эффективности противовирусного препарата Ингавирин ${ }^{\circledR}$, капсулы 90 мг (ОАО "Валента Фарм", Россия), для экстренной внутриочаговой профилактики.

Параллельное наблюдение за контрольной группой позволило дифференцировать профилактичес- кий эффект Ингавирина ${ }^{\circledR}$ от естественного течения эпидемического процесса.

Эпидемические очаги представляли собой общежития (13 очагов), студенческие группы (28) и семьи (2). При возникновении случаев заболевания с признаками респираторной инфекции, подтвержденной вирусологическими методами (иммуноферментный анализ - ИФА, полимеразная цепная реакция - ПЦР), лица, контактировавшие с источником инфекции в очаге, включались в исследование не позднее 48 ч после контакта.

В исследовании сравнивались 2 группы контактных лиц, сформированные методом простой рандомизации с использованием генератора случайных чисел статистического пакета программ SPSS 12.0, Chicago, Illinois.

Период наблюдения в очагах составил 37 дней (7-дневный период приема Ингавирина ${ }^{\circledR} /$ плацебо и 30-дневный период наблюдения). Со 2-го по 7-й день исследования наблюдение проводилось ежедневно, далее - каждые 5 дней (рис. 1).

Заболевшим из числа контактных лицам, у которых в ходе исследования было подтверждено ОРВ3 неосложненного течения, проводилась симптоматическая терапия (местные сосудосуживающие препараты, отхаркивающие средства, рутин, аскорбиновая кислота, глюконат кальция, антигистаминные препараты). При $\mathrm{t} \geq 38^{\circ} \mathrm{C}$ разрешался самостоятельный прием парацетамол-содержащих препаратов (однократно, внутрь). Для верификации диагноза проводилось вирусологическое исследование (ИФ, ПЦР). В случае развития симптомов ОРВЗ в первые 7 дней исследования прием Ингавирина ${ }^{\circledR} /$ плацебо продолжался до окончания профилактического курca. В первые 3 дня болезни за пациентами наблюдали ежедневно, далее - на 5-е $( \pm 1)$ и 10-е $( \pm 2)$ сутки.

В исследование включались лица обоего пола в возрасте 18-65 лет, имеющие постоянный контакт с источником ОРВИ (с вирусологически подтвержденным диагнозом) в очаге, не позднее 48 ч с момента первого контакта, не имеющие тяжелых, декомпенсированных или нестабильных соматических заболеваний, не принимавшие интерфероны и иммуномодулирующие препараты менее чем за 3 мес. до начала исследования, не вакцинировавшиеся от гриппа или прошедшие вакцинацию от гриппа более года назад и давшие информированное согласие на участие в исследовании. Не включали в исследование беременных и женщин в период лактации.

В зависимости от вида профилактики (Ингавирин $^{\circledR} /$ плацебо) были сформированы группы участников исследования. Первую группу составили пациенты, принимавшие Ингавирин ${ }^{\circledR}$ по 1 капсуле

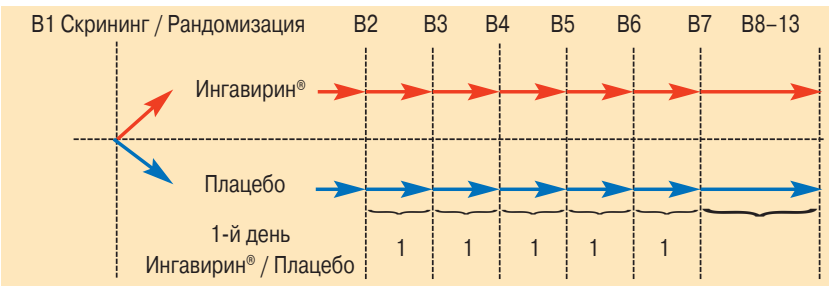

Рис. 1. Схема исследования 
1 раз в день в течение 7 дней. Вторую - лица, получавшие плацебо по 1 капсуле 1 раз в день на протяжении 7 дней после включения в исследование.

\section{Критерии эффективности}

Для оценки эффективности профилактики ОРВЗ использовались:

1. Индекс эффективности (ИЭ), определяемый как соотношение заболеваемости в группе плацебо (\%) к заболеваемости в группе Ингавирина ${ }^{\circledR}(\%)$. Заболеваемость - отношение числа новых случаев заболевания среди контактных лиц к числу контактных лиц, находящихся под риском возникновения заболевания на начало периода наблюдения в группе, умноженное на $100 \%$.

2. Коэффициент эффективности (КЭ), являющийся показателем защищенности препаратом, рассчитывали по формуле:

$$
\frac{\left(\begin{array}{c}
\text { заболеваемость в группе }-\begin{array}{c}
\text { заболеваемость в группе } \\
\text { плацебововирина }
\end{array}
\end{array}\right) \times 100 \%}{\text { Заболеваемость в группе плацебо }}
$$

3. Относительный риск (ОР) развития ОРВ3 определяли как отношение риска развития заболевания в группе Ингавирина ${ }^{\circledR}$ к риску развития заболевания в группе плацебо.

У заболевших контактных лиц оценивались сроки развития заболевания, продолжительность периода лихорадки, сроки нормализации температуры тела, частота встречаемости, продолжительность и выраженность симптомов интоксикации и катаральных симптомов в динамике. Выраженность симптомов оценивалась пациентом и исследователем по 4-балльной шкале: 0 баллов - отсутствие симптома; 1 - минимальная выраженность симптома; 2 - умеренная выраженность симптома; 3-максимальная выраженность симптома.

\section{Анализ и статистическая обработка данных}

Расчет размера выборки основывался на предположении об ожидаемом снижении риска развития ОРВ3 в группе Ингавирина ${ }^{\circledR}$ на $\geq 50 \%$ (ИЭ $\geq 2$ ) по сравнению с плацебо (при ожидаемом уровне заболеваемости в группе плацебо $16 \%$ ). При статистической мощности $80 \%$, уровне $\alpha$-ошибки $5 \%$ и при условии равного размера групп в исследование было необходимо включить не менее 400 человек, которые случайным образом должны быть рандомизированы в 2 равные группы (по 200 человек).

Проверка статистических гипотез по результатам настоящего исследования проводилась при априор- ном уровне значимости ( $\alpha$-ошибке), равном 0,05 . Поправка на множественные сравнения не делалась.

Статистическая обработка данных производилась с использованием программного пакета SPSS 17.0 (Chicago, Illinois). Расчет объема выборки осуществлялся с помощью компьютерной программы WinPepi 11.

\section{Результаты}

Исследование проводилось в 2 исследовательских центрах. В 1-м центре количество участников составило 100 человек, во 2-м - 300, возрастной состав участников в 2 центрах не отличался. Скринингу подверглись 406 человек. Из них 2 человека отказались принимать участие в исследовании, 4 - не соответствовали критериям включения. В каждую сравниваемую группу было рандомизировано и включено по 200 участников. В исследовании приняли участие 227 женщин и 173 мужчин в возрасте от 18 до 59 лет $(21,9 \pm 3,0)$.

Проведенное исследование выявило достоверные различия в количестве заболевших контактных лиц в сравниваемых группах. В период с 1-го по 7-й день в 1-й группе число заболевших составило 10 (5,0 \%) человек, а во 2-й группе - 27 (13,5\%), что в 2,7 раза больше $(p=0,003)$. В течение всего периода исследования с 1-го по 37-й день в группе Ингавирина ${ }^{\circledR}$ заболели 15 человек из 200 (7,5\%), а в группе плацебо - 32 из $200(16 \%)(p=0,009)$. В период с 8-го по

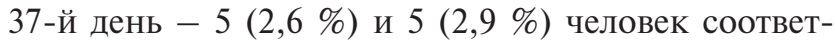
ственно (рис. 2, табл. 1). Таким образом, 78,7 \% всех случаев заболевания в 2 группах произошло в первые 7 дней исследования: $27 \%(n=10)$ в группе Ингавирина ${ }^{\circledR}$ и $73 \%(n=27)$ в группе плацебо. Незаболевшие контактные лица закончили исследование по

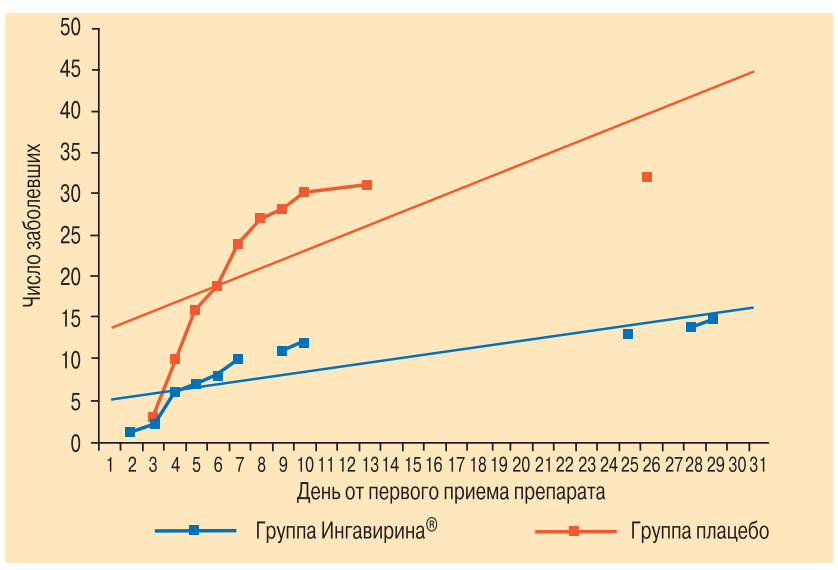

Рис. 2. Число заболевших контактных лиц в сравниваемых группах

Таблица 1

Эффективность профилактики ОРВЗ в сравниваемых группах

\begin{tabular}{|c|c|c|c|c|c|}
\hline \multirow{2}{*}{$\begin{array}{c}\text { Период исследования, } \\
\text { дни }\end{array}$} & \multicolumn{2}{|c|}{$n / N^{*}$} & \multirow[t]{2}{*}{$\mathrm{OP}^{* *}$ (95 \% дИ) } & \multirow[t]{2}{*}{ иэ*** (95 \% ди) } & \multirow[t]{2}{*}{$p$} \\
\hline & Ингавирин ${ }^{\circledast}$ & Плацебо & & & \\
\hline c 1-го по 7-й & $10 / 200$ & 27 / 200 & $0,37(0,18-0,75)$ & $2,7(1,34-5,43)$ & 0,003 \\
\hline c 8-го по 37-й & $5 / 190$ & $5 / 173$ & $0,91(0,21-4,02)$ & $1,1(0,29-4,01)$ & 0,88 \\
\hline с 1-го по 37-й & $15 / 200$ & 32 / 200 & $0,47(0,22-0,81)$ & $2,13(1,19-3,82)$ & 0,009 \\
\hline
\end{tabular}

Примечание: * - n - число контактных лиц, заболевших ОРВЗ, N - число контактных лиц, с риском развития заболевания; ** ОР - отношение риска развития ОРВЗ в группе Ингавирина ${ }^{\oplus}$ к риску развития ОРВЗ в группе плацебо; *** ИЭ - индекс эффективности и соответствующий ему 95\%-ный ДИ (доверительный интервал). 
Таблица 2

Коэффициент эффективности профилактики ОРВЗ Ингавирином ${ }^{\circledR}$

\begin{tabular}{|l|c|c|r|}
\hline $\begin{array}{c}\text { Период иссле- } \\
\text { дования, дни }\end{array}$ & Ингавирин ${ }^{\oplus}, \boldsymbol{n} / \mathbf{N}$ & Плацебо, $\boldsymbol{n} / \mathbf{N}$ & КЭ, $\%$ \\
\hline с 1-го по 7-й & $10 / 200$ & $27 / 200$ & 63,00 \\
\hline с 8-го по 37-й & $5 / 190$ & $5 / 173$ & 8,95 \\
\hline с 1-го по 37-й & $15 / 200$ & $32 / 200$ & 53,10 \\
\hline
\end{tabular}

протоколу (185 человек в группе Ингавирина ${ }^{\circledR}$ и 168 человек в группе плацебо). Выбывших или исключенных после рандомизации лиц не было.

Коэффициент эффективности (КЭ), или показатель защищенности препаратом, в период с 1-го по 7-й день исследования составил 63 \% (табл. 2). В период с 8-го по 37-й день наблюдалась тенденция к снижению риска развития ОРВ3 в группе Ингавирина ${ }^{\circledR}$, но она не была статистически значимой $(p=$ $0,88)$. Показатель защищенности препаратом в этот период составил 8,95\%. За весь период наблюдения за контактными лицами (с 1-го по 37-й день) Ингавирин ${ }^{\circledR}$ статистически значимо, в сравнении с плацебо, снизил риск развития заболевания $(\mathrm{OP}=0,47$ $(0,22-0,81), p=0,01 ;$ ИЭ $=2,13(1,19-3,82), p=0,01)$, при этом показатель защищенности препаратом (КЭ) составил $53 \%$.

\section{Характеристика клинических симптомов ОРВ3 у заболевших контактных лиц}

Эпидемический сезон 2010-2011 гг. в РФ характеризовался социркуляцией вирусов гриппа А подтипов (H1N1, H1N1swl-2009, H3N2), гриппа B, парагриппа, аденовируса и респираторно-синцитиального вируса. Активность вирусов гриппа регистрировалась с 3-й по 10-ю нед. 2011 г., а вирусов не гриппозной этиологии - в течение всего сезона подъема заболеваемости ОРВ3, начиная с 40-й нед. 2010 г. Следует отметить, что в структуре вирусов не грип- позной этиологии преобладал вирус парагриппа. Вторым по значимости был аденовирус (данные мониторинга ОРВ3 на территории РФ сотрудничающих центров ВО3 - ФГБУ "НИИ гриппа" и ФГБУ "НИИ вирусологии им. Д.И.Ивановского") (информационные материалы ВО3, сообщение № 135 от 03.06.11) (рис. 3).

Общее число заболевших пациентов в сравниваемых группах составило 47 человек (35 женщин и 12 мужчин). В группе пациентов, получавших с целью экстренной профилактики Ингавирин ${ }^{\circledR}$, заболели 15 человек, в группе получавших плацебо - 32. Во всех случаях заболевание имело среднетяжелое, неосложненное течение.

Вирусологический анализ показал, что грипп А / H1N1 (сезонный штамм) был выявлен у 2 заболевших. В остальных 45 случаях определена ОРВИ негриппозной этиологии (табл. 3).

У заболевших пациентов в сравниваемых группах температура тела не превышала $38,0{ }^{\circ} \mathrm{C}$, средние значения этого показателя в 1-е сут. заболевания статистически значимо не различались и составили $37,8 \pm 0,6{ }^{\circ} \mathrm{C}$ в группе Ингавирина ${ }^{\circledR}$ и $37,7 \pm 0,5{ }^{\circ} \mathrm{C}$ в группе плацебо $(p=0,827)$. Лихорадочный период (температура тела, измеренная в подмышечной впадине $\geq 37,5{ }^{\circ} \mathrm{C}$ ) у пациентов 1 -й группы был ограничен первыми сутками заболевания, а у пациентов 2-й группы его продолжительность составила 2 сут. (рис. 4).

Основные симптомы ОРВ3 (головная боль, ринит и фарингит) в группе Ингавирина ${ }^{\circledR}$ исчезали достоверно быстрее. Уже на 2-е сут. болезни головная боль в этой группе встречалась в 2 раза реже ( $p=$ 0,038 ), а на 5-е сут. ринит и фарингит встречались соответственно в 2,3 раза и в 2,2 раза реже, по сравнению с группой плацебо ( $p=0,022$ и $p=0,012$ соответственно) (табл. 4). Средняя продолжительность головной боли у заболевших контактных лиц в группе Ингавирина ${ }^{\circledR}$ составила 2,7 сут., что статистически

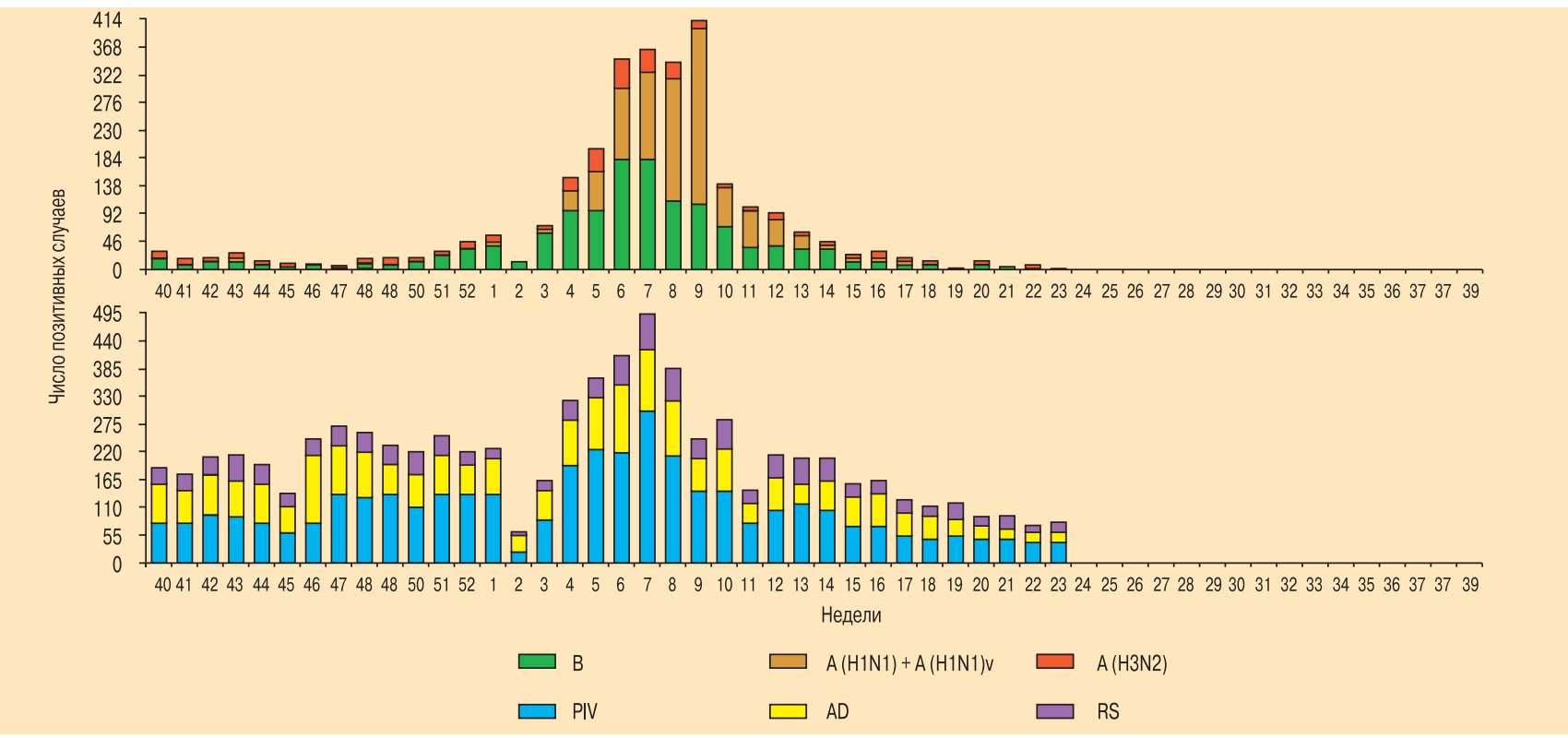

Рис.3. Результаты выявления возбудителей гриппа и других ОРВИ с использованием иммунофлюоресцентного метода на территории РФ (по состоянию на 23-ю нед. 2011 г.) 
Шульдяков А.А. и др. Клинико-эпидемиологическая эффективность противовирусного препарата Ингавирин ${ }^{\circledR}$

Таблища 3

Этиологическая характеристика ОРВ3 у заболевиих контактных лиц,

\begin{tabular}{|l|c|c|c|} 
& 1 -я группа, $n(\%)$ & 2-я группа, $n(\%)$ & $p^{*}$ \\
\hline Грипп А / H1N1 & $1(6,7)$ & $1(3,1)$ & 0,5 \\
\hline Другие ОРВИ: & $14(93,3)$ & $31(96,9)$ & 0,5 \\
\hline аденовирус & $5(33,3)$ & $10(31,2)$ & 1,0 \\
РС-вирус & $1(6,7)$ & $2(6,2)$ & 1,0 \\
\hline Парагрипп: & $8(53,3)$ & $19(59,4)$ & 0,8 \\
\hline І типа & $5(33,3)$ & $11(34,4)$ & 1,0 \\
ІІІ типа & $3(20,0)$ & $8(25,0)$ & 1,0 \\
\hline
\end{tabular}

Примечание: * - статистическая значимость межгрупповых различий в заболеваемости инфекциями оценивалась с использованием точного критерия Фишера; РС-вирус - респираторно-синцитиальный вирус.

значимо меньше продолжительности этого симптома в группе плацебо - 4,4 сут. ( $p=0,045)$.

Выраженность катаральных симптомов - ринита и кашля, оцениваемых по 4-бальной шкале (0-3 балла), в группе Ингавирина ${ }^{\circledR}$ составила $1,55 \pm 0,69$ и $1,00 \pm 0,00$ балла соответственно и была достоверно меньше, по сравнению с группой плацебо (2,12 \pm 0,77 и 1,30 $\pm 0,47$ балла, $p=0,04$ и 0,01 соответственно).

Сроки развития заболевания в исследуемых группах не различались.

На протяжении всего периода наблюдения неблагоприятных явлений, связанных с приемом препарата Ингавирин ${ }^{\circledR}$, зарегистрировано не было.

\section{Обсуждение}

В настоящее время известны 2 группы противовирусных препаратов. Блокаторы ионного канала белка М2 - амантадин и ремантадин - препятствуют проникновению вируса в клетку за счет предотвращения диссоциации РНП-комплекса и М1 белка виpуса. В данный период времени ВО3 не рекомендует их использование в связи с высокой устойчивостью вирусов гриппа ко всем препаратам этой группы. Ингибиторы нейраминидазы - осельтамивир и занамивир - активны в отношении вирусов гриппа А и В за счет нарушения механизмов проникновения и почкования. В доступной литературе есть сведения о результатах только 1 исследования осельтамивира по постконтактной профилактике гриппа, в котором показано, что применение препарата в дозе 75 мг в сутки на протяжении 7 дней уменьшает частоту ла-

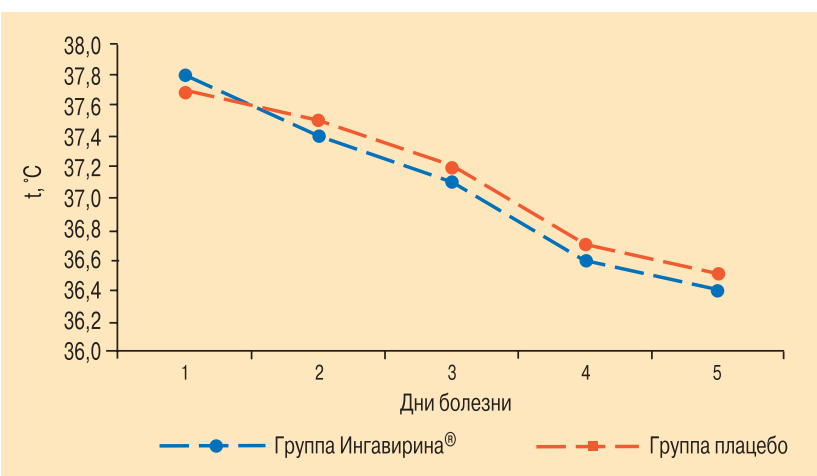

Рис. 4. Средние максимальные значения температуры у заболевших контактных лиц в сравниваемых группах
Таблица 4

Частота встречаемости основных симптомов ОРВЗ у заболевших контактных лиц,

\begin{tabular}{|c|c|c|c|}
\hline $\begin{array}{c}\text { Симптомы / срок } \\
\text { от начала болезни }\end{array}$ & $\begin{array}{c}\text { Группа Ингавирина } \\
\text { абс. }(\%)\end{array}$ & $\begin{array}{c}\text { Группа плацебо, } \\
\text { абс. }(\%)\end{array}$ & $p$ \\
$\begin{array}{c}\text { Головная боль } \\
\text { 2-е сут. }\end{array}$ & $5(33,33)$ & $21(65,63)$ & $0,038^{*}$ \\
$\begin{array}{c}\text { Ринит } \\
\text { 5-е сут. }\end{array}$ & $4(26,67)$ & $20(62,50)$ & $0,022^{*}$ \\
$\begin{array}{c}\text { Фарингит } \\
\text { 5-е сут. }\end{array}$ & $5(33,33)$ & $23(71,88)$ & $0,012^{*}$ \\
\hline
\end{tabular}

Примечание: ${ }^{\star}-$ тест $\chi^{2}$ Пирсона.

бораторно подтвержденной гриппозной инфекции до 1 \% [18]. Результаты другого исследования по профилактической эффективности осельтамивира свидетельствуют о том, что препарат не прекращает передачу инфекции при длительных, тесных контактах между людьми [19]. Препараты этой группы могут вызывать побочные эффекты, такие как диспепсия и бронхоспазм. Учитывая, что в предпандемический период до 90 \% вирусов гриппа А / H1N1 оказались резистентны к осельтамивиру, ВОЗ в период пандемии гриппа 2009 г., несмотря на чувствительность пандемического вируса к ингибиторам нейраминидазы, не рекомендовала прием этих препаратов в целях профилактики, т. к. при массовом применении препаратов этой группы можно ожидать значительного роста числа резистентных штаммов за счет мутаций в нейраминидазе [20].

Известно, что прекращение передачи вирусной инфекции при длительных тесных контактах между людьми невозможно только за счет лечения заболевших. Важную роль для прерывания путей передачи инфекции и в борьбе с эпидемией играет профилактика, повышающая протективный эффект более чем на 50 \% [21]. Результаты проведенного исследования свидетельствуют о том, что противовирусный препарат Ингавирин ${ }^{\circledR}$ является эффективным средством внутриочаговой профилактики ОРВ3 среди контактных лиц в эпидемическом очаге. При ежедневном приеме в течение 7 дней, препарат достоверно снижает заболеваемость среди контактных лиц на $63 \%$ и уменьшает риск развития ОРВЗ в 2,7 раза (ИЭ = 2,7; OP =0,37). 30-дневная защитная эффективность Ингавирина ${ }^{\circledR}$, при условии ежедневного приема препарата в течение предшествующих 7 дней, заключается в снижении риска развития ОРВ3 в 2,1 раза $($ ИЭ = 2,1), при этом показатель защищенности препаратом (КЭ) составляет 53 \%. Эпидемиологическая эффективность Ингавирина ${ }^{\circledR}$ сопоставима с другими препаратами, используемыми для профилактики ОРВ3 в РФ [22].

У заболевших контактных лиц, принимавших в качестве профилактического средства Ингавирин $^{\circledR}$, продолжительность периода лихорадки была на сутки короче, наблюдалось более легкое течение ОРВ3, о чем свидетельствует достоверно меньшая продолжительность головной боли, а также достоверно меньшая продолжительность и выраженность катаральных симптомов по сравнению с группой плацебо. 


\section{ИнгавИрИн}

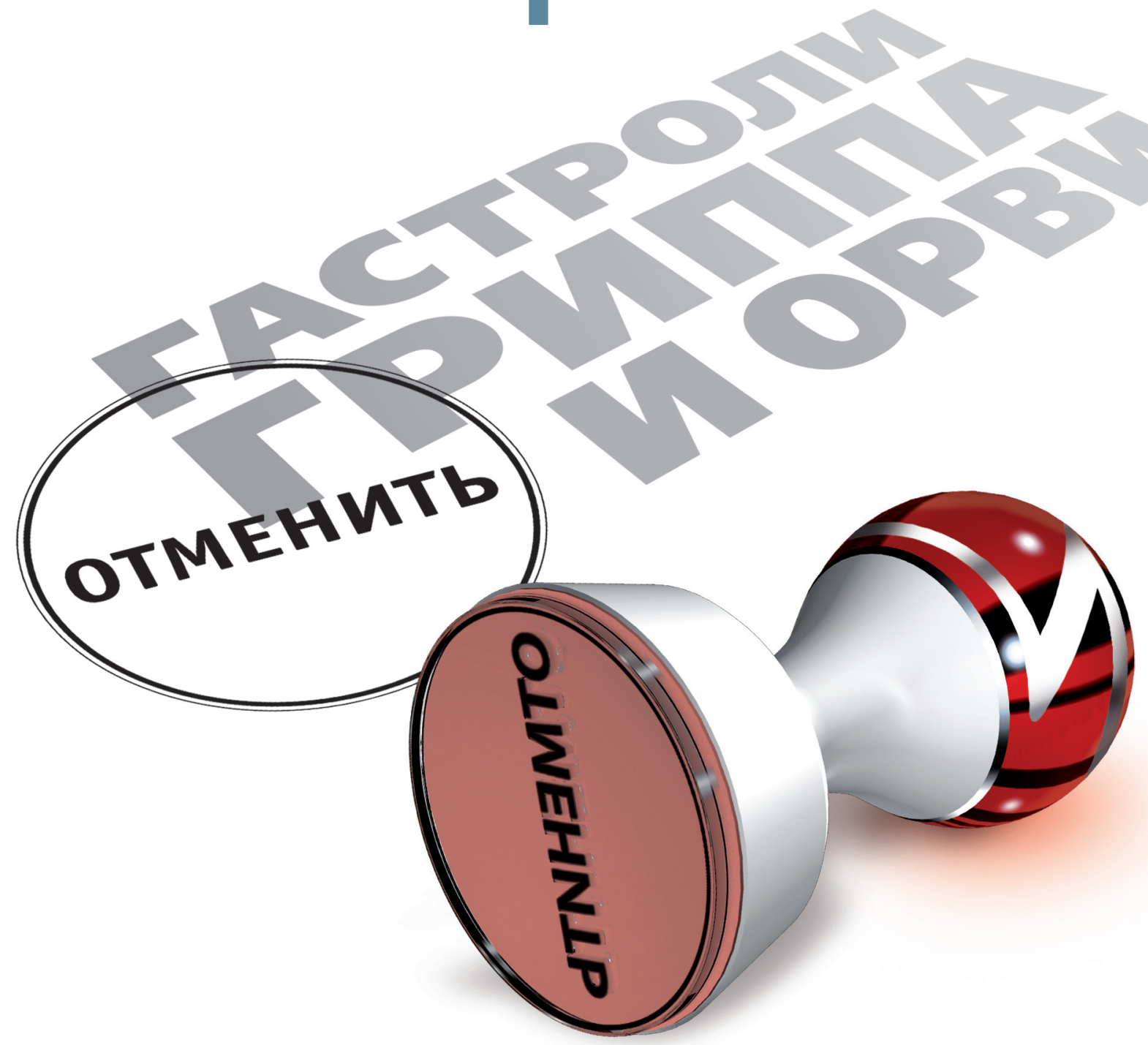

\section{Инновашионный противовирусный препарат А^я лечения и профилактики}

- Оказывдет прямое противовирусное действие в отношении вирусов гриппа и ОРВИ

- Сокрашдет продолжительность и уменьшает выраженность симптомов гриппа и ОРВИ

- Снижает риск развития осложнений и рециАивов

- Облалает высоким профилем безопасности

- Обеспечивает максимальную комплаентность (1 капсула 1 раз в сутки, 5-7 Аней)

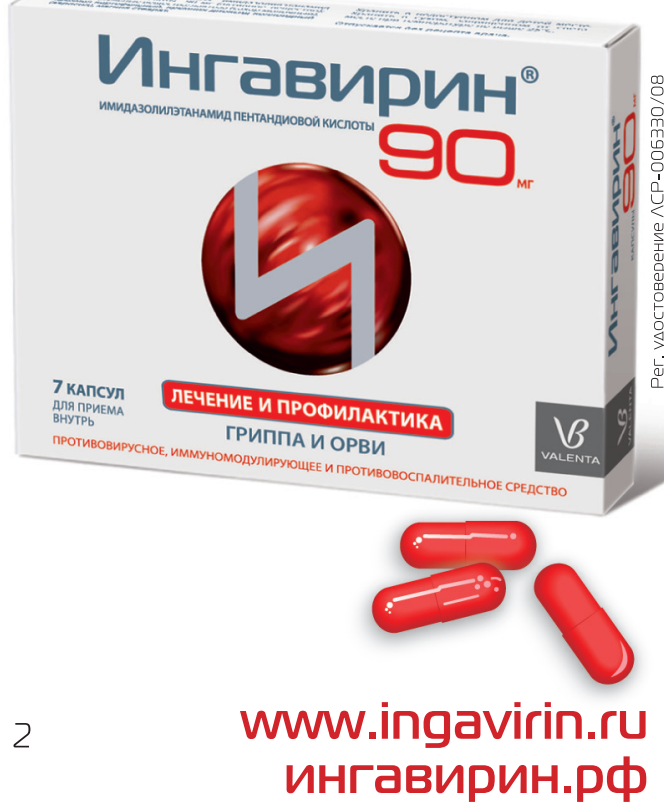


Ингавирин ${ }^{\circledR}$ как противовирусный препарат соответствует всем требованиям, предъявляемым к современным препаратам неспецифической профилактики респираторных инфекций в период сезонного подъема заболеваемости ОРВИ. Он эффективно защищает контактных лиц от заболевания в очаге инфекции, обладает широким спектром активности в отношении вирусов гриппа и эпидемически наиболее значимых ОРВИ негриппозной этиологии (аденовирус, вирус парагриппа). Препарат имеет низкую токсичность и высокий профиль безопасности, проявляющийся в отсутствии побочных / нежелательных явлений, высоко комплаентен, а риск развития резистентности вирусов к препарату минимален.

Результаты проведенного исследования позволяют рекомендовать Ингавирин ${ }^{\circledR}$ в качестве средства неспецифической профилактики ОРВЗ у взрослых.

\section{Литература}

1. ВОЗ. Информ. бюл. 2009; № 211, апр.

2. Онищенко Г.Г., Ежлова Е.Б., Лазикова Г.Ф. и др. Пандемия гриппа A / H1N1 / 09 в мире и Российской Федерации в 2009-2010 гг. и прогноз на 2010-2011 гг. Журн. микробиол. 2010; 6: 12-17.

3. Allander T., Taani M.T., Bjerkner A. et al. Cloning of human parvovirus by molecular screening of respiratory tract samples. Proc. Natl Acad. Sci. USA 2005; 102: 12 891-12 896.

4. van den Hoogen B.G., de Long J.C., Groen J. Et al. A newly discovered human pnemovirus isolated from young children with respiratory tract disease. Nature Med. 2001; 7: 719-724.

5. Hamelin M.E., Abed Y., Boivin G. Human metapneumovirus: a new player among respiratory viruses. Clin. Infect. Dis. 2004; 38: $983-390$.

6. Чучалин А.Г. Синдром острого повреждения легких. Рус. мед. журн. 2006; 14 (22): 1582.

7. Schildgen O., Geikowski T., Glatzel T. et al. New variant of the human metapneumovirus associated with in an acute and severe exacerbation of asthma bronchiole. J. Clin. Virol. 2004; 31: 283-288.

8. Coronavirus SARS-agent causes atypical pneumonia (recommendation of WHO and $\mathrm{CDC}$ ). Information new release / Покровский В.В., Малеев В.В., Киселев О.И. и др. StPetersburg; Moscow; 2003.

9. Чешик С.Г., Вартанян Р.В. Респираторно-синцитиальная вирусная инфекция: клиника, диагностика, лечение. Дет. инфекции 2004; 1: 43-46.

10. Устойчивость к осельтамивиру у госпитализированных пациентов с ослабленным иммунитетом. ВОЗ. Краткое сообщение № 18 от 2 дек. 2009 г.

11. Логинова С.Я., Борисевич С.В., Максимов В.А. и др. Изучение лечебной эффективности нового отечественного препарата Ингавирин ${ }^{\circledR}$ в отношении возбудителя гриппа А (H3N2). Антибиотики и химиотер. 2008; 53 (7-8): 27-30.

12. Логинова С.Я., Борисевич С.В., Лыков М.В. и др. Изучение активности Ингавирина ${ }^{\circledR}$ in vitro в отношении "мексиканского" пандемического подтипа H1N1 вируса гриппа A, штаммы A / California / 04 / 2009 и A / California / 07 / 2009. Антибиотики и химиотер. 2009; 54 (3-4): 15-17.

13. Зарубаев В.В., Кривицкая В.З., Небольсин В.Е. и др. Экспериментальное изучение противовирусной активности Ингавирина ${ }^{\circledR}$ в отношении вируса парагриппа человека. Антибиотики и химиотер. 2010; 55 (7-8): 13-16.

14. Зарубаев В.В, Слита А.В., Сироткин А.К. и др. Экспериментальное изучение противовирусной активности Ингавирина ${ }^{\circledR}$ в отношении аденовируса человека. Антибиотики и химиотер. 2010; 55 (9-10): 19-24.
15. Колобухина Л.В., Малышев Н.А., Меркулова Л.Н и др. Эффективность Ингавирина ${ }^{\circledR}$ в лечении гриппа у взрослых. Tep. apx. 2009; 3: 54-57.

16. Колобухина Л.В., Меркулова Л.Н, Григорян С.С. и др. Эффективность и безопасность препарата Ингавирин ${ }^{\circledR}$ в лечении гриппа и других ОРВИ у взрослых. Справочник поликлин. врача 2010; 9: 1-6.

17. Колобухина Л.В., Меркулова Л.Н., Щелканов М.Ю. и др. Пандемический грипп в России: отличительные особенности клинического течения и отсутствие ранней этиотропной терапии как фактор риска развития тяжелых форм заболевания. Тер. арх. 2011; 9: 48-53.

18. Welliver R., Monto A.C., Carewicz O. et al. Effectiveness of oseltamivir in preventing influenza in household contacts: a randomized controlled trial. J. A.M.A. 2001; 285: 748-754.

19. Hayden F.G., Atmar R.L., Schilling M. et al. Use of the selective oral neuraminidase inhibitor oseltamivir to prevent influenza. N. Engl. J. Med. 1999; 341: 1336-1343.

20. Использование противовирусных препаратов и риск развития лекарственной устойчивости. ВОЗ. Краткое сообщение № 12 от 25 сент. 2009 г.

21. Hayden F.G., Belshe R., Villanueva C. et al. Management of influenza in households: a prospective, randomized comparison of oseltamivir treatment with or without post exposure prophylaxis. J. Infect. Dis. 2004; 189: 440-449.

22. Каира А.Н., Ющенко Г.В., Ахмадуллина Р.Р., Черкасова Н.А. Неспецифическая профилактика гриппа и острых респираторных вирусных инфекций препаратом Анаферон на территории Московской области. Инфекц. бол. 2005; 3 (3): 64-67.

\section{Информация об авторах}

Шульдяков Андрей Анатольевич - д. м. н., проф., зав. кафедрой инфекционных болезней и эпидемиологии в ГБОУ ВПО "Саратовский государственный медицинский университет им. В.И.Разумовского"; e-mail: shuldaykov@mail.ru

Ерофеева Марианна Константиновна - д. м. н., старший научный сотрудник, руководитель лаборатории испытаний новых средств защиты против вирусных инфекций в ФГБУ "НИИ гриппа" Минздравсоцразвития России; e-mail: erofeeva@influenza.spb.ru

Кузнецов Владимир Иванович - д. м. н., доцент кафедры инфекционных болезней в ГБОУ ВПО "Саратовский государственный медицинский университет им. В.И.Разумовского", e-mail: vikuz47@yandex.ru Ляпина Елена Павловна - д. М. н., проф. кафедры инфекционных болезней и эпидемиологии в ГБОУ ВПО "Саратовский государственный медицинский университет им. В.И.Разумовского"; e-mai: LMN_SON @rambler.ru

Позднякова Марина Георгиевна - к. м. н., старший научный сотрудник лаборатории испытаний новых средств защиты против вирусных инфекций в ФГБУ "НИИ гриппа" Минздравсоцразвития России; e-mail: pozdnjakova72@ mail.ru

Максакова Величка Лазарова - к. м. н., ведущий научный сотрудник лаборатории испытаний новых средств защиты против вирусных инФекций в ФГБУ "НИИ гриппа" Минздравсоцразвития России; e-mail: maksakova@influenza.spb.ru

Котова Ольга Сергеевна - лаборант-исследователь, младший научный сотрудник лаборатории испытаний новых средств защиты против вирусных инфекций в ФГБУ "НИИ гриппа" Минздравсоцразвития России; e-mail: olga kotova@influenza.spb.ru

Амосова Ирина Викторовна - к. б. н., старший научный сотрудник лаборатории биотехнологии диагностических препаратов ФГБУ "НИИ гриппа" Минздравсоцразвития России; e-mail: amosova.23@ mail.ru Амосова Ирина Викторовна - к. б. н., старший научный сотрудник в лаборатории биотехнологии диагностических препаратов в ФГБУ "НИИ гриппа" Минздравсоцразвития России; e-mail: amosova.23@ mail.ru Шелехова Светлана Евгеньевна - младший научный сотрудник в лаборатории испытаний новых средств защиты от вирусных инфекций в ФГБУ "НИИ гриппа" Минздравсоцразвития России; тел.: (812) 499-15-36

Бузицкая Жанна Валерьевна - к. б. н., старший научный сотрудник в лаборатории молекулярной вирусологии и генной инженерии ФГБУ "НИИ гриппа" Минздравсоцразвития России; тел.: (812) 499-15-20; e-mail: janna@influenza.spb.ru

Гиль Артем Юрьевич - к. м. н., ассистент кафедры общественного здравоохранения и профилактической медицины факультета управления и экономики здравоохранения ГОУ ВПО "Первый Московский государственный медицинский университет"; тел.: (499)246-19-59; еmail: artyom5@mail.ru

Поступила 21.08.12 (с) Коллектив авторов, 2012 удК [616.98:578.832.1]-085.281.8 


\section{Комментарии экспертов}

Профилактическая эффективность Ингавирина ${ }^{\circledR}$ в предотвращении ОРВ3, вызванных вирусами гриппа, парагриппа, адено- и респираторно-синцитиальными вирусами, циркулирующими в эпидсезон с октября 2010 г. по апрель 2011 г. у взрослых, проживающих в сообществе и входящих в группу высокого риска по заражению, была изучена в 2 центрах в рамках двойного слепого рандомизированного плацебоконтролируемого исследования. Участники (проживающие в общежитии, студенческие группы и 2 семейных очага) были рандомизированы по виду профилактики в 2 группы: получающие Ингавирин ${ }^{\circledR}$, капсулы 90 мг (1-я группа) или плацебо (2-я группа) 1 раз в день в течение 7 дней. Мониторинг проводился в течение 7 дней. Конечной точкой была доля участников, у которых в ходе профилактики развился симптомокомплекс ОР3, этиологический диагноз которого был подтвержден методом ОТ-ПЦР.

Авторами показано, что у достоверно меньшего количества участников в группе Ингавирина ${ }^{\circledR}$ развились признаки ОРЗ с повышением температуры тела. Результат соответствует защитной эффективности 63 \%. У заболевших в группе Ингавирина ${ }^{\circledR}$ основные симптомы болезни (головная боль, ринит, фарингит) протекали легче и исчезали достоверно быстрее. В целом за период наблюдения с 1-го по 37-й день Ингавирин ${ }^{\circledR}$ достоверно снизил риск развития заболевания. При этом коэффициент защиты составил $53 \%$.

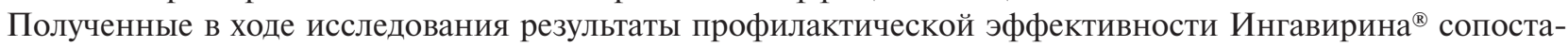
вимы с защитным эффектом противовирусных препаратов, используемых в России в аналогичных эпидемических очагах.

Руководитель лаборатории респираторных вирусных инфекций с апробацией лекарственных средств ФГУ "НИИ вирусологии им. Д.И.Ивановского", д. м. Н., профессор Колобухина Л.В.

Развитие современного скоростного транспорта, тесные международные контакты, массовая миграция населения, паломничество и туризм способствуют быстрому распространению возбудителей ОРВИ по всему миру. С годами процесс их распространения будет только ускоряться. При этом удельный вес возбудителей в структуре острых респираторных вирусных заболеваний будет сезонно меняться как в отдельных регионах, так и в межрегиональном, межгосударственном масштабе. Поэтому исследования, проведенные специалистами 2 исследовательских центров, посвященные выявлению клинико-эпидемиологической эффективности Ингавирина ${ }^{\circledR}$ в очагах ОРВИ в период подъема заболеваемости являются актуальными и значимыми для российской науки и здравоохранения.

Авторы в период с октября 2010 г. по апрель 2011 г. организовали и успешно провели в эпидемических очагах (общежитиях, студенческих группах и семьях) двойное слепое рандомизированное плацебоконтролируемое исследование эффективности противовирусного препарата Ингавирин ${ }^{\circledR}$ для экстренной внутриочаговой профилактики (задействовано 400 человек). Важно отметить, что для дифференцирования профилактического эффекта Ингавирина ${ }^{\circledR}$ от естественного течения эпидемического процесса специалисты грамотно задействовали контрольную группу, а для идентификации возбудителей у больных использовали наиболее эффективные молекулярно-биологические и иммунохимические диагностические методы (ИФА, ПЦР).

Оценка эффективности Ингавирина ${ }^{\circledR}$ проведена в соответствии с требованиями регулирующих документов по проведению клинических исследований безопасности и эффективности фармакологических веществ (определение индекса и коэффициента эффективности, относительного риска развития заболевания ОРВИ). Авторы грамотно (с использованием современного программного обеспечения) провели статистическую обработку данных, позволившую выявить достоверные различия в количестве заболевших контактных лиц в сравниваемых группах. Обобщенные результаты эффективности Ингавирина ${ }^{\circledR}$ в отношении ОРВИ представлены в 2 рис. и 4 табл.

Результаты проведенного исследования в 2 центрах Санкт-Петербурга и Саратова свидетельствуют о том, что противовирусный препарат Ингавирин ${ }^{\circledR}$ является эффективным средством внутриочаговой профилактики ОРВИ среди контактных лиц в эпидемическом очаге. При ежедневном приеме в течение 7 дней препарат достоверно снижает заболеваемость среди контактных лиц и уменьшает риск развития ОРВИ. При этом эпидемиологическая эффективность Ингавирина ${ }^{\circledR}$ сопоставима с другими препаратами, используемыми для профилактики ОРВИ в РФ.

Особо следует отметить, что результаты исследований на большом контингенте лиц подтвердили не только высокую противовирусную эффективность Ингавирина ${ }^{\circledR}$, но и высокий профиль его безопасности, проявляющийся в отсутствии побочных / нежелательных явлений. Все это позволяет рекомендовать Ингавирин ${ }^{\circledR}$ как средство неспецифической профилактики ОРВИ у взрослых.

Начальник Вирусологического центра ФГКУ "33 ЦНИИИ Минобороны России", д. б. н., к. м. Н., профессор С.В.Борисевич 